\title{
Craniofacial Fibrous Dysplasia Addressed Through the Intraoral and Nasal Access
}

Ivo Cavalcante Pita-Neto1, Júlio Leite Araujo Junior², Milana Drumont RamosSantana1, Hermes Melo Teixera Batista', Eduardo Costa Studart Soares ${ }^{3}$, Luiz Carlos De Abreu', Luciano Miller Reis Rodrigues ${ }^{1}$, Woneska Rodrigues Pinheiro', Glauco Soares de Almeida 4

\section{Abstract}

Background: The Craniofacial Fibrous Dysplasia is a benign disease, pseudoneoplasic, rare and asymptomatic of slow growth promoting replacement of bone tissue by an amorphous connective tissue, promoting bone deformation that can invade and cause compression of important structures such as the skull base and facial orbital bone. This study aims to present a clinical case of a Craniofacial Fibrous Dysplasia, emphasizing an alternative of an aesthetic surgical access by an intraoral approach.

Case Report: We report the clinical case of patient IMS, 21 years of age with craniofacial fibrous dysplasia presenting deformity of the left facial middle third in orbital, nasal and maxilla region who was submitted to surgery for facial recontouring. The surgical access was intraoral associated with access for rhinoplasty. A lesion scrape was realized for facial recontouring and nasal osteotomy for correction of deviation caused by the injury.

Conclusions: It was concluded that the surgical technique associated with the intraoral access with nasal extension is an important tool in addressing these lesions, allowing a large surgical field and satisfactory aesthetic and functional results without facial scars.

\section{Introduction}

The fibrous dysplasia of jaws has been known for years as a bone injury of the primary hyperparathyroidism, believed by some researchers in 1891 [1]. Only in 1938, after extensive studies observed an isolated
1 Laboratory of Study Design and Scientific Writing, ABC Faculty of Medicine.

2 Academic of dentistry course, Leão Sampaio Faculty.

3 Professor of Maxillofacial Surgery, Ceará Federal University.

4 Ceará Federal University.

Contact information:

Ivo Cavalcante Pita Neto.

”ivopita@gmail.com

Keywords

Maxilla, Fibrous Dysplasia,

Surgical technique. 
form of the injury, which led them to determine a new terminology, fibrous dysplasia of the jaws, as it is known nowadays [2, 3]

The fibrous dysplasia is a bone neoclassical pseudo disorder, which has affinity for young women, having as a disadvantage its slow asymptomatic and recurrent growth, however it is benign [4]. Depending on their location, it can cause compression of important structures such as the facial orbital bone and skull base. The craniofacial fibrous dysplasia has an amorphous connective tissue caused by the proliferation of fibroblasts interspersed in trabeculae of an immature bone without surrounded osteoblasts. As the spinal bone cavity is gradually replaced by bone fibrous connective tissue in an interlaced form, where spindle cells led to bone deformation. The term fibrous dysplasia of jaws is suitable for neurocranium injuries [5].

The present study aims to present a case of Craniofacial Fibrous Dysplasia, emphasizing an alternative of aesthetic surgical access by an intraoral approach avoiding facial scars.

\section{Case Report}

Patient IMS, female, without systemic changes, reported swelling in the left cheek when she was 8 years old. It was diagnosed as craniofacial fibrous dysplasia; she was submitted to a facial recontouring surgery. At 17 years old she returns with an aesthetic complaint caused by a further increase in size representing recurrence of the lesion, causing deformation in orbital, nasal and left maxilla region. There was a clear facial asymmetry with nasal, maxilla and dental average line deviation (figure 1). A computed tomography (CT) revealed a radiopaque lesion with a ground-glass appearance in the left jaw region of approximately $7 \mathrm{~cm}$ of diameter and extension to the base of the skull (figure 2). The neurosurgical evaluation ruled out compression of brain structures. The scintigraphic study showed homogeneous distribution of the radiopharmaceutical in the skeleton, except for the increase of diffuse heterogeneous uptake involving the majority of the left facial bones with increased osteogenic activity. There was no focus of evidence of intense activity of the neurocranium suggesting absence of lesion growth in the prime areas.

A surgical treatment was indicated for removal of the majority of the lesion located in the middle third of the face and to promote facial recontouring. Under general anesthesia an intraoral approach was realized in anterior maxillary alveolar mucosa, nasal mucosa incision isolating the nostrils and union of these incisions with the

Figure 1: Facial asymmetry with nasal, maxilla and dental average line deviation.

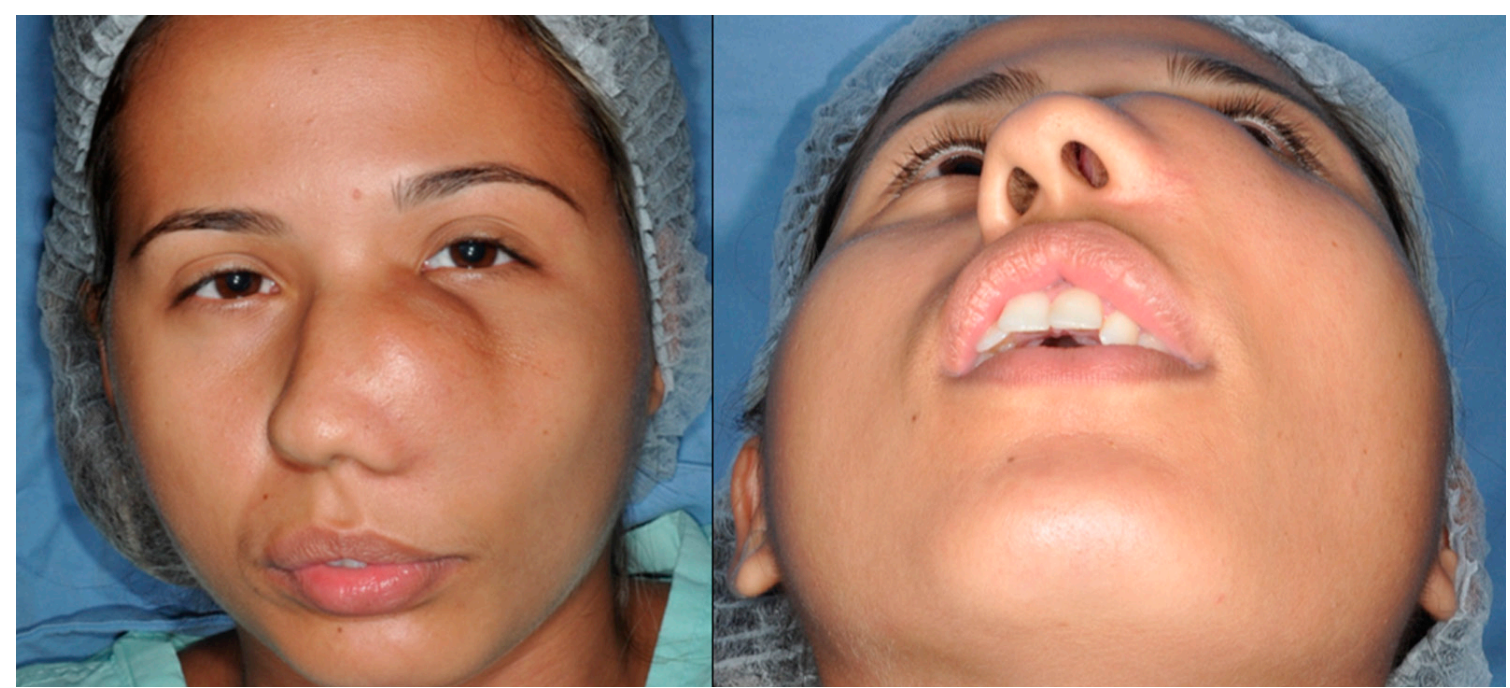


Figure 2: Deformation in orbital, nasal and left maxilla region.

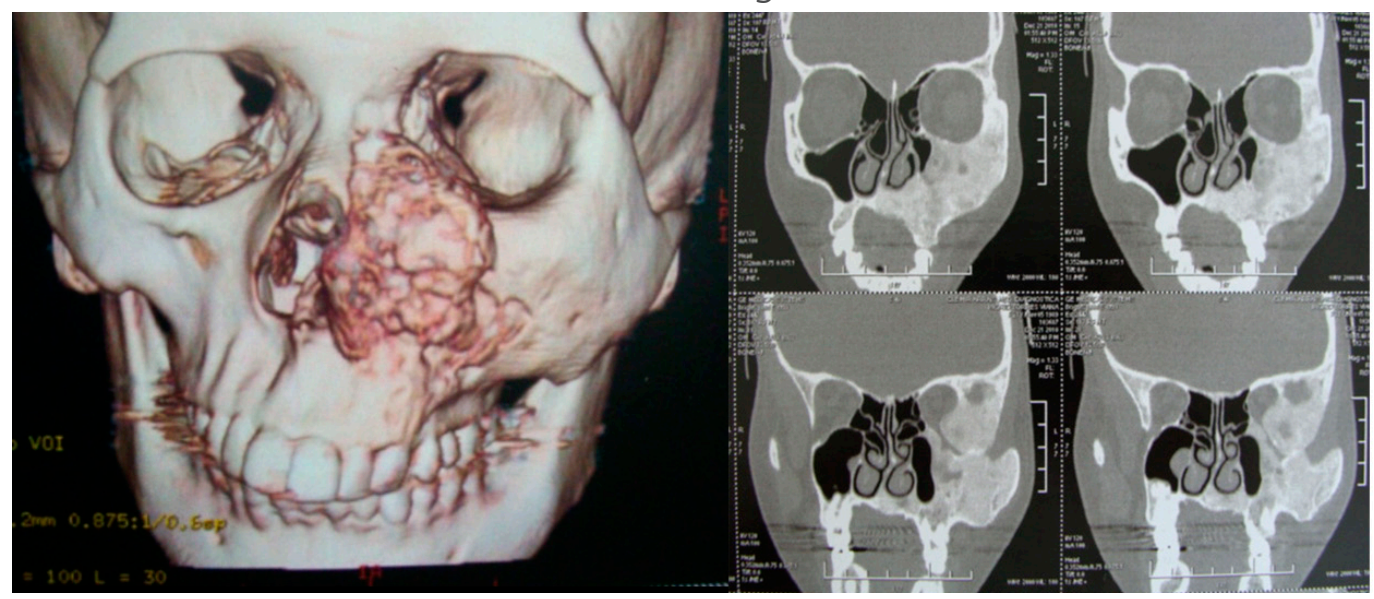

intraoral access, allowing the mucoperiosteal deunion in the intraoral access with the access for tachment in the right and left maxillae, exposing rhinoplasty offered a wide surgical field around the the bone-cartilaginous structures in the nose with facial middle third and degloving (figure $3 \mathbf{a}, \mathbf{3 b}$ ). its skin shifted upward along the upper lip. The Through previous planning by facial prototyping

Figure 3a: The Union In The Intraoral Access With The Access For Rhinoplasty.

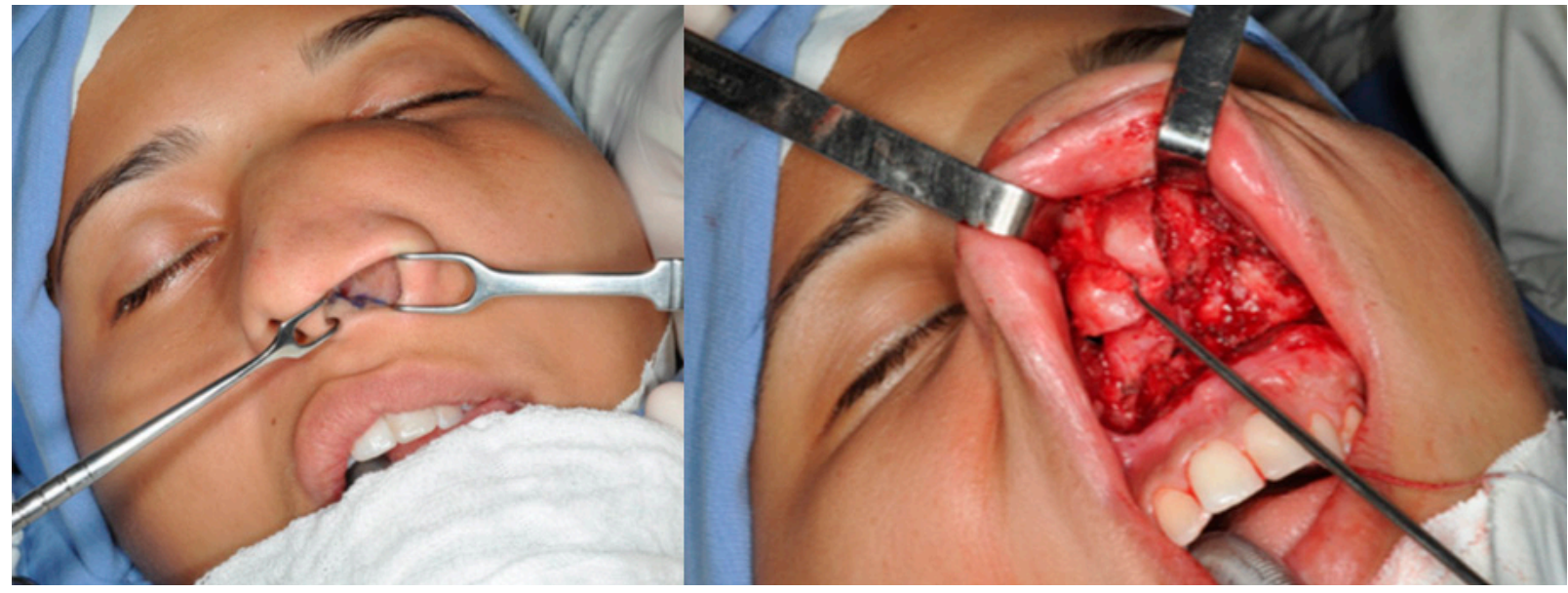

Figure 3b: Facial degloving and lesion exposure.

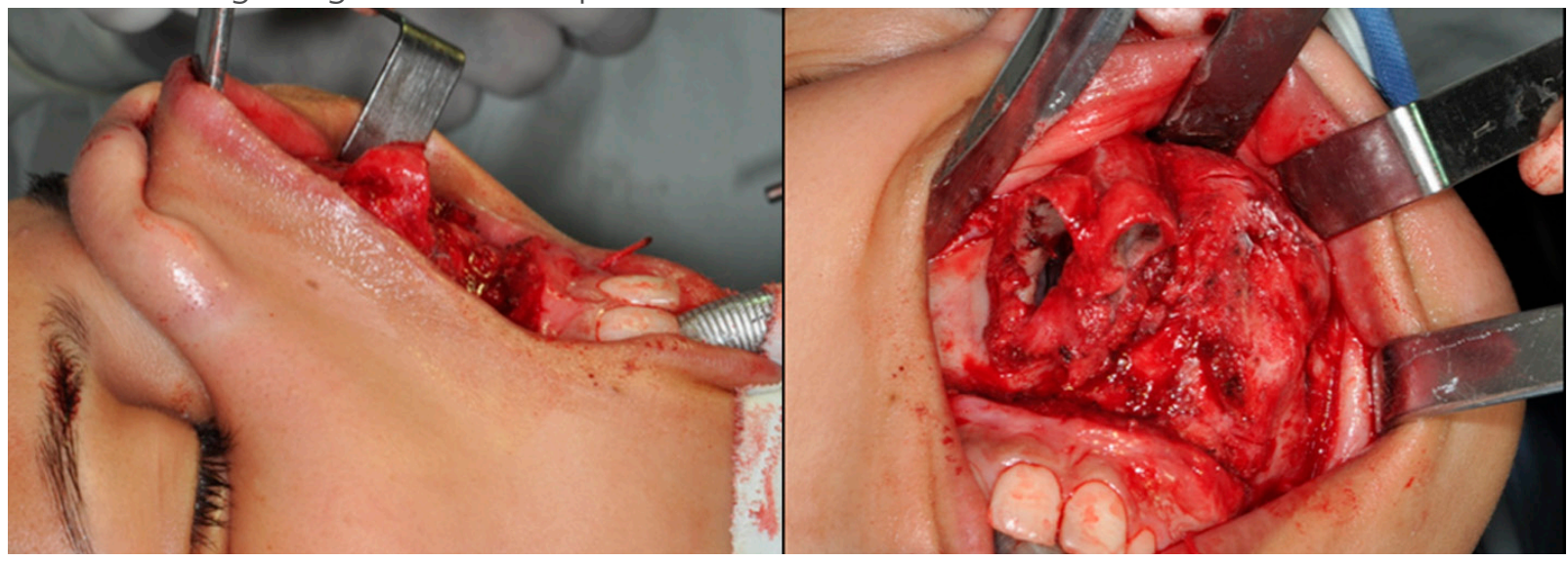


(figure 4), there was the removal and scrape off facial external injury promoting facial recontouring, associating rhinoplasty with nasal osteotomies and correction of the deviation caused by the expansion of the lesion (figure 5).

In postoperative follow-up of up to two years, there was a satisfactory cosmetic accommodation of the tissue, improved symmetry and absences of facial scars, making the access of choice an important tool in addressing these lesions with these characteristics (figure 6).

Figure 4: Previous planning by facial prototyping.

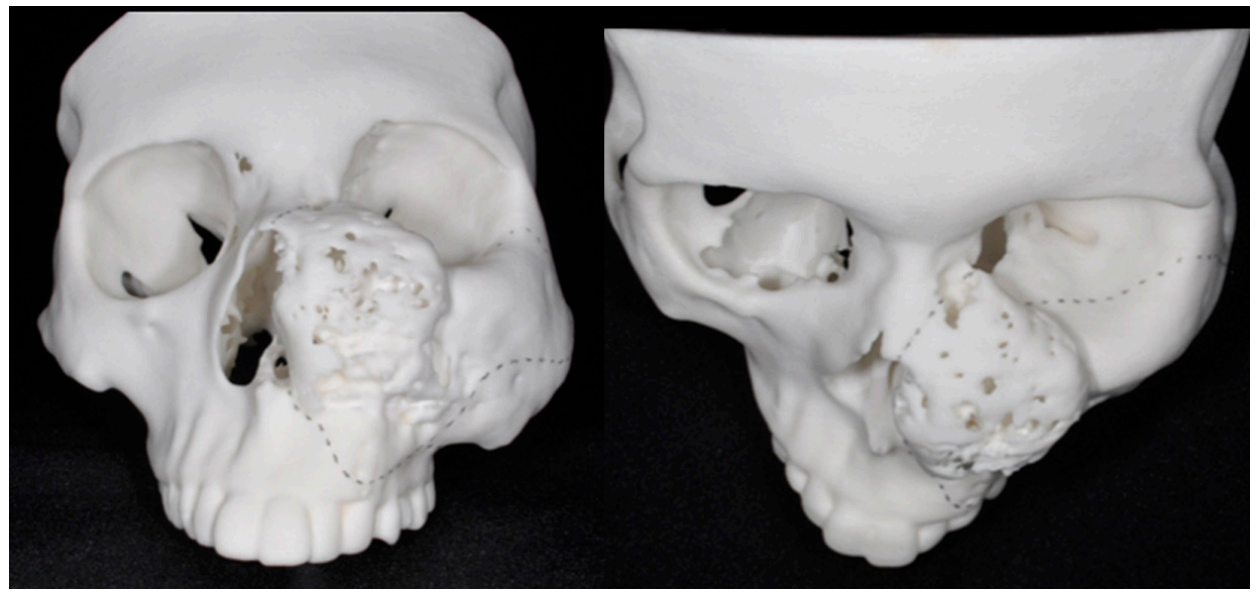

Figure 5: Recontouring Associated The Rhinoplasty With Nasal Osteotomies.

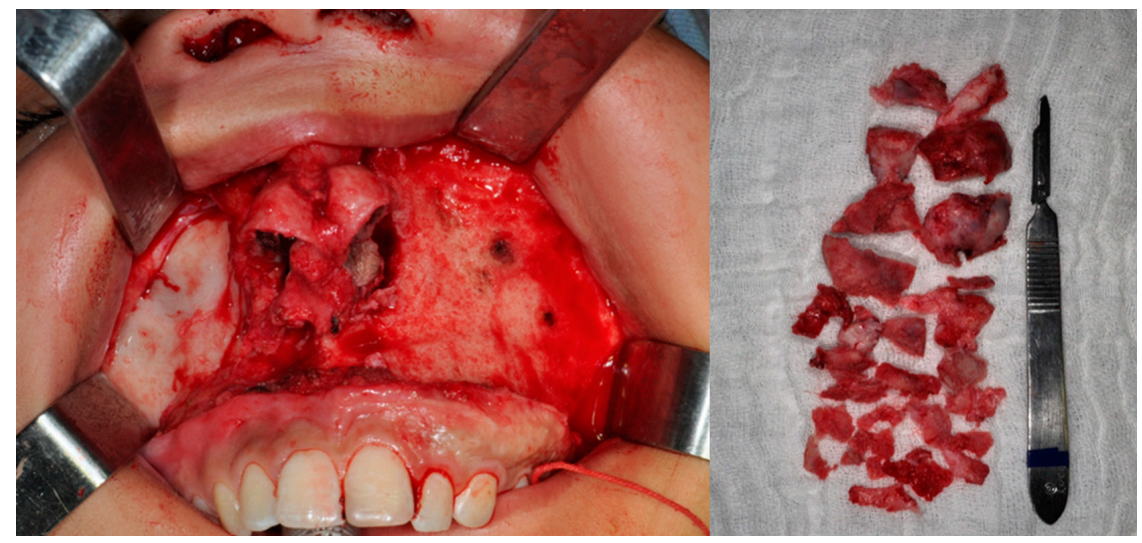

Figure 6: Satisfactory cosmetic accommodation of the tissue, improved symmetry and absences of facial scars.

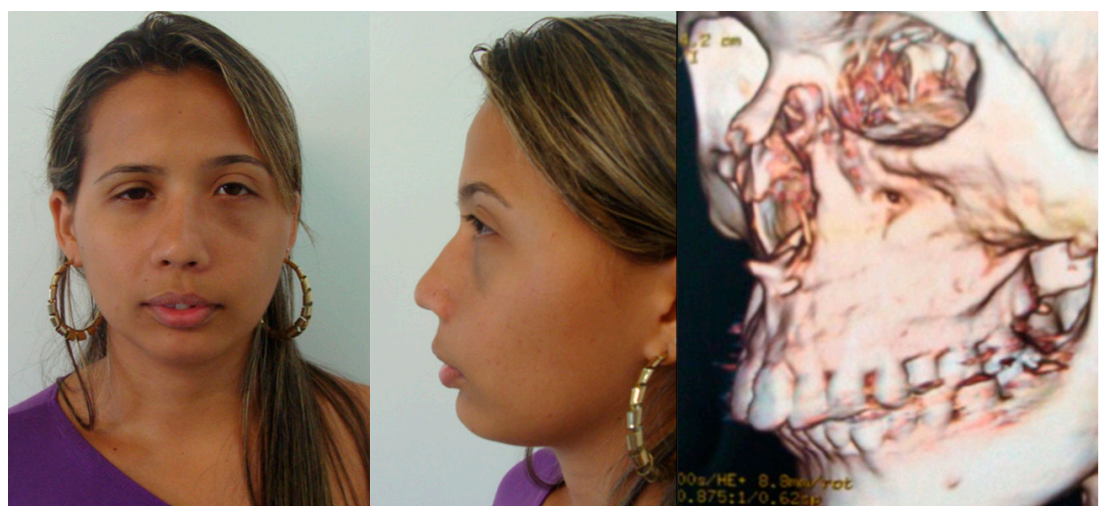




\section{Discussion}

Several studies have been devoted to the study of fibrous dysplasia of the jaws, but the study in question shows a rare condition of simultaneous involvement in cranial and facial region $[6,7]$

The craniofacial region is an important site for the pathology onset, being the maxilla and mandible the featured sites. The patient had no evidence of lesion in the mandible [8].

The fibrous dysplasia of maxillae can be divided into two groups, monostotic and polyostotic. The monostotic form is considered the most common, affecting only one bone or contiguous bones, corresponding to approximately $70 \%$ of cases $[8,9]$. When the disease occurs in two or more bones without continuity, it corresponds to the polyostotic form, representing $30 \%$ of cases. When the fibrous dysplasia appears accompanied by skin pigmentations of the type of "coffee with milk" and endocrine diseases it is called McCune-Albright syndrome [10].

In patients with fibrous dysplasia presenting the polyostotic form, it was observed that most of these patients presented craniofacial involvement, being one side of the body most affected. In a better way, most patients with fibrous dysplasia in the craniofacial region have the monostotic fibrous dysplasia form as prevalent [9].

The observations made by other authors are consistent with relation to the appropriate designation for neurocranium involvement $[5,11]$

With regards to the standard states that the monostotic form has no predilection for gender. However the polyostotic form has a predilection for females [8].

Regarding the etiology, the literature is also confusing and divergent. The author Lichtenstein [2], believes there is an abnormal enzymatic activity in the process of mesenchymal bone formation. But Murray [12], supports the hypothesis that there is a change in calcium and phosphorus metabolism. Attention to the occurrence of os- teoblastic hyperplasia [13]. However the monostotic form of this disorder could not be correlated with the syndromes of Albright and polyostotic fibrous dysplasia [14].

There are several divergences related to its pathophysiological, where several authors defend the idea that the monostotic fibrous dysplasia is a deviation from the normality of the mesenchymal bone formation process, being a congenital abnormality of dominant or recessive autosomal transmission [14].

Malignant and benign lesions make themselves as differential on the diagnosis of craniofacial dysplasia of the jaws. Injuries such as, solitary unilocular cysts, not ossifying fibroma, eosinophilic granuloma, cholesteatoma, meningioma, Paget's disease, osteochondroma, ossifying fibroma, giant cell reparative granuloma, exostosis, aneurysmal bone cyst, cystic fibrous osteitis, ameloblastoma, and plasma cell myeloma. Injuries such as sarcoma and metastatic osteoblastic lesions are considered malignant lesions of diagnosis. Observed an occurrence of $0.4 \%$ of spontaneous neoplastic transformation to sarcoma $[15,16]$.

The craniofacial fibrous dysplasia can be treated by surgical technique and / or drugs. Being the surgery indicated only for symptomatic cases or in cases of functional changes, anatomical distortion of the bones involved, to prevent bone expansion and pathological fractures [17, 18]

The case of fibrous dysplasia, the radiotherapy becomes a contraindication because it can increase the malignant degeneration, not being this a predictor factor of malignancy, since in rare cases, the spontaneously sarcomatous transformation has been reported. Radiotherapy was not contemplated to the patient, and the emphatic literature contraindicates its use. The patient is being evaluated periodically because of the possibility of recurrence and she has been oriented $[3,19,20]$ 


\section{Conclusions}

The fibrous dysplasia is a lesion that has several characteristics in common with other fibro-osseous pathologies. It is of extreme importance to get as much information, through clinical, imaging, laboratory and histopathological examinations to reach a correct, early diagnosis and appropriate treatment. Several discrepancies was observed in the literature and it was concluded that the Craniofacial Fibrous Dysplasia is a fibro-osseous pathology that still has several obscure fields because of lack of research.

For the dental surgeon, it is important to have knowledge of this condition, as this disease can affect orofacial structures.

Ideally, the treatment should be performed after the growth period is finished, however, in cases involving the aesthetic and functional aspects severely; it is advisable to intervene before adulthood. The follow up is very important, being important in the early detection of possible recurrence, reactivation or malignant changes.

\section{Consent}

Written informed consent was obtained from the patient for publication of this Case report and any accompanying images.

\section{Ethics questions}

The ethical committee of the Regional Hospital of Cariri, for case presentation, approved the current study.

\section{Competing interests}

The authors declare no conflicts of interest. All research was conducted with their own resources. rces and did not receive financial aid from any institution.

The authors state that they did not receive financial aid from any institution (political, personal, religious, ideological, academic, intellectual, commercial, or any other).

\section{References}

1. Sannomiya, E. K. et al. Aspectos radiográficos da displasia fibrosa craniofacial: relato de um caso clínico. Rev. Pós Grad 2004, v. 11, n. 2, p. 201-206.

2. Lichtenstein L, Jaffe HL. Fibrous dysplasia of bone. Arch Pathol 1942; 33: 777-816.

3. Huller, T. E.; Lusting, L. R. Paget's disease and fibrous dysplasia. Otolaryngol. Clin. North Am., 2003 v. 36, n. 4, p. 707-732.

4. Alves AL, Canavarros F, Vilela DSA, et al. Displasia fibrosa: relato de três casos. Rev Bras Otorrinolaringol 2000;68(2):288-92.

5. Selva D, White VA, O'Connell JX, Rootman J. Primary bone tumors of the orbit. Surv Ophthalmol. 2004;49(3):328-42.

6. Tokano, H. et al. Sequencial computed tomography images demonstrating characteristic changes in fibrous dysplasia. J. Laryngol. Otol 2001 v. 115, n. 9, p. 757-759.

7. Schipper, J. et al. Computer-assisted surgery (CAS) for the optimal treatment of craniofacial fibrous dysplasia. HNO. 2005, v. 53, n. 9 , p. $766-772$

8. Som PM, Curtin HD. Head and neck imaging. 4th ed. New York, NY: Mosby, 2004.

9. Chen YR, Wong FH, Hsueh C, Lo LJ. Computed tomography characteristics of non-syndromic craniofacial fibrous dysplasia. Chang Gung Med J 2002;25:1-8.

10. Contran RS, Kumar V, Robbins SL. Robbins Patologia estrutural e funcional. $5^{a}$ ed. Rio de Janeiro, RJ: Guanabara Koogan, 1996.

11. Ricalde, P.; Horswell, B. B. Craniofacial fibrous dysplasia of the fronto-orbital region: a case series and literature review. J. Oral Maxillofac. Surg 2001 v. 59, n. 2, p. 157-167.

12. Murray RC, Kirkpatrick HJR, Forrai E. Case of Albright's syndrome (osteitis fibrosa disseminata). Br J Surg 1946; 34: 48-57.

\section{Financial resources}

The authors state that they used their own resou- 
13. Changus GW. Osteoblastic hyperplasia of bone. A histochemical appraisal of fibrous dysplasia of bone. Cancer 1957; 10: 115761.

14. Schlumberger HG. fibrous dysplasia of single bones (monostotic fibous dysplasia). Milit Surgeon 1947; 99:504-27.

15. Oliveira, RCB et al. Displasia fibrosa do osso temporal: relato de dois casos. Revista Brasileira de Otorrinolaringologia, São Paulo. Brasil, 2004 v. v.70, n.n.5, p. 695-700

16. Schwartz DT, Alpert M. The malignant transformation of fibrous dysplasia. Am J Med Sci 1964; 247:35-54.

17. Castellanos González JA, Leal Mursulí A, Adefna Pérez RI, et al. Osteoblastoma monostótico costal: presentación de un caso y re- visión de la literatura / Costal monostotic osteoblastoma: a case report and literature review. Rev Cuba Cir 2009;48(1):

18. Soares VYR, Silva TO, Cunha RLLS, et al. Displasia fibrosa recidivante de antro maxilar com invasão de base do crânio. Arq Int Otorrinolaringol 2009;13(3):331-5.

19. Smoutha E, Edelstein D, Parisier S. Fibrous dysplasia involving the temporal bone: report of three new cases. Am J Otol 1987; 8(2): 103-7.

20. Gross CW, Montgomery WW. Fibrous dysplasia and malignant degeneration. Arch Otolaryngol 1967; 85:653-7.

\section{Comment on this article:}

\section{(f) $[$ in $8+\mathbf{S}$ ?}

.

\section{http://medicalia.org/}

Where Doctors exchange clinical experiences, review their cases and share clinical knowledge. You can also access lots of medical publications for free. Join Now!

\section{Publish with iMedPub}

\section{http://www.imed.pub}

International Archives of Medicine is an open access journal publishing articles encompassing all aspects of medical science and clinical practice. IAM is considered a megajournal with independent sections on all areas of medicine. IAM is a really international journal with authors and board members from all around the world. The journal is widely indexed and classified Q1 in category Medicine. 